\title{
Truck Driver Dies When Tractor-Trailer Leaves The Road And Plunges Into A Creek-Bed
}

\section{Incident Number: 13KY039}

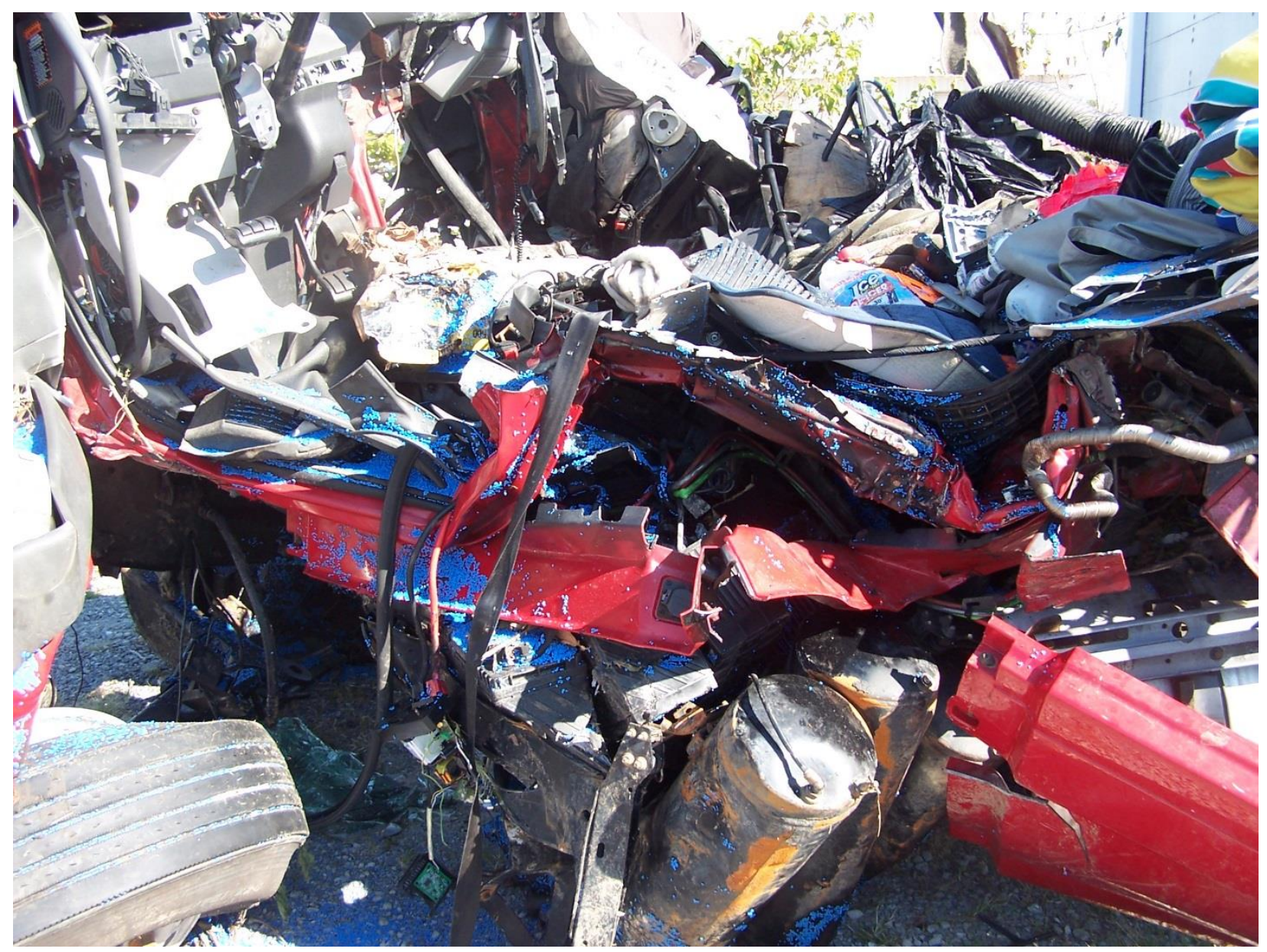

The Tractor involved in the crash. Photograph property of KY FACE program

Kentucky Fatality Assessment and Control Evaluation Program Kentucky Injury Prevention and Research Center 333 Waller Avenue Suite 242

Lexington, Kentucky 40504

Phone 859-323-3981 Fax 859-257-3909

www.kiprc.uky.edu

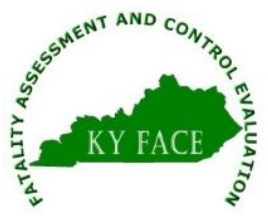


Kentucky Fatality Assessment and Control Evaluation (FACE) Program Incident Number: 13KY039

Release Date: November 20, 2013

Subject: Truck Driver Dies When Tractor-Trailer Leaves The Road And Plunges Into A Creek-Bed

\section{Summary:}

In the early morning hours of a fall day, exact time unknown and the length of time driving unknown, a 28-year-old male truck driver was driving north on an interstate transporting 30,000 lbs. of blue plastic injection molding pellets. The truck driver exited the highway behind a guardrail and traveled 1,320 feet, striking a wire fence and several trees before plummeting into a creek bed, shearing the cab open. At 10:27 a.m., a citizen called in to the fire department to report a mysterious blue substance observed in the creek a couple of miles down from the accident. The fire department arrived on scene, followed the creek and found the semi in the creek. The driver was extricated by mechanical means by the fire department and declared dead at the scene by the coroner's office.

To prevent future occurrences of similar incidents, the following recommendations have been made:

Recommendation No. 1: Semi tractor-trailer drivers should routinely receive refresher training to recognize signs of fatigue and drowsiness and when to seek appropriate rest periods.

Recommendation No. 2: Never turn off your airbags while driving a tractor-trailer.

Recommendation No. 3: Motor carriers need to monitor their drivers' driving records for key violations that indicate a future crash is likely.

Recommendation No. 4: Motor carriers should consider regular online safety training that allows drivers the flexibility to complete course(s) at times convenient to their busy schedules.

\section{Background}

The semi-truck was a 2007 Volvo. The driver was a 28 -year-old man with a four-year-old son and wife 8 months pregnant with their second child. The company had 10 tractors and 12 trailers with 7 drivers. The trucking company was based in a midwest state and transported general freight but not hazardous materials. The company had been in business since April 10, 2007. It 
is not known how long the driver was employed with the company or how long he had been a truck driver. It is known that the driver was foreign born.

On the day of the incident, the temperature ranged from 64-67 degrees Fahrenheit in the early morning with precipitation.

\section{Investigation}

The driver was traveling north on a four lane interstate highway, in the early morning hours. Traffic was light and the roads were wet from rain. The speed limit in the area was $70 \mathrm{MPH}$. The driver had picked up his load 336 miles south and was heading north for a total length of 678 miles on his trip. Drive time to his destination was a total of eleven hours and 10 minutes. The driver was halfway to his destination when the semi-truck left the roadway for unknown reasons.

The tractor trailer exited the roadway on the right side of the interstate, traveled down a culvert and through a wire fence taking down trees before nosediving into a creek. From where the semi-truck left the interstate, it was approximately 1,320 feet to the creek bed. There were no skid marks or brake marks on the pavement prior to leaving the interstate lane. The force of the collision caused the fifth wheel to rip away from the tractor but remained on the trailer as the trailer came up over the cab. The driver became trapped in the semi-tractor. There were no other motorists who witnessed the crash.

A citizen who lived along the creek called the fire department to report a mysterious blue substance in the downstream area of the creek at 10:27 a.m. Firefighters arrived on the scene at 10:35 a.m. They walked and traced the creek to where the substance had been reported, and discovered the trapped body of the 28-year-old driver. According to firefighters, the 28-year-old had been dead for several hours. The jaws of life were used to remove his body, which was transported to the coroner's office where an autopsy was performed. The autopsy revealed that the 28-year-old died of multiple blunt force trauma. The autopsy did not reveal any presence of drugs in the driver's system or any medical condition that would have caused him to lose consciousness.

The driver exited the interstate and curved area, just inches before a guardrail system was installed. There were no vehicular factors detected and no environmental factors detected. The human factor in this crash was "not under proper control". No avoidance maneuver was reported and the driver's speed was unknown. The driver was wearing his seat belt. Airbags were installed but not deployed. The airbags switch was off. Due to the absence of skid marks on the highway, it is possible the driver was distracted or fell asleep; the exact root cause could not be determined.

\section{Cause of Death}


The cause of death was multiple blunt force trauma due to a motor vehicle crash.

\section{Recommendations and Discussion:}

Recommendation No. 1: Semi tractor-trailer drivers should routinely receive refresher training to recognize signs of fatigue and drowsiness and when to seek appropriate rest periods.

Besides distraction, fatigue is one of the main difficulties drivers combat. Drivers should be educated to recognize when they are becoming fatigued while driving. According to an article, "Driver Fatigue: The Dangers of Driving Sleepy", signs of driver fatigue include daydreaming, straying out of the lane, excessive yawning, feeling impatient and/or stiff, heavy eyes, and reacting slowly. Another article states that over-steering is also a sign of driver fatigue. The study "The development of a naturalistic data collection system to perform critical incident analysis: An investigation of safety and fatigue issues in long-haul trucking" states that most incidents involving fatigued drivers occur in the late afternoon and early evening hours with the highest rates occurring between 11:00 am to noon and 3:00 pm to 6:00 pm. Methods to avoid driver fatigue include being well rested, getting enough sleep, taking breaks every two hours where the driver may take a nap, eating a snack, avoiding consumption of alcohol, having a trip driving plan, and staying hydrated. Every driver should have a route plan that incorporates appropriate rest areas to give the driver access to meals, a quiet safe place to nap, and the ability to stretch. The plan should also provide information on roadside assistance if needed.

\section{Recommendation No. 2: Never turn off your airbags while driving a tractor-trailer.}

Motor vehicle crashes are the leading cause of death for individuals 5-27 years old. Air bags reduce the risk of dying in a direct frontal crash by about 30 percent. Air bags have saved over 25,782 lives in the U.S. from 1987 through 2008. They also have prevented a large number of serious head and chest injuries. Overall, air bags add to the protection offered by seat belts. In the vast majority of cases, adults are safer with an air bag that is "on."

Recommendation No. 3: Motor carriers need to monitor their drivers' driving records for key violations that indicate a future crash is likely.

Motor Carriers need to routine monitor their drivers' driving records and their violations to determine who is at a higher risk of crashing due to unsafe driving behaviors. Motor Carriers need to meet with the high-risk drivers and address these behaviors to prevent future crashes.

Recommendation No. 4: Motor carriers should consider regular online safety training that allows drivers the flexibility to complete course(s) at times convenient to their busy schedules.

Motor carriers should consider providing laptops or similar training devices to their drivers for required monthly safety training sessions. 
Keywords

Driver fatigue

Driver distraction

Airbags

Training

\section{References}

http://www.fmcsa.dot.gove/facts-research/research-technology/report/intelligent-transportationtruckparking.htm

http://www.sleep-deprivation.com/articles/casues-of-sleep-deprivation/driver-fatigue.php http://www.distraction.gov/research/PDF-Files?Driver-Distraction-Commercial-VehicleOperations.pdf

http://www.rta.nsw.gov.au/roadsafety/fatigue/index.html

http://www.nhtsa.dot.gov/

\section{Acknowledgements}

The Kentucky FACE program would like to thank the employer, towing company, the coroner and WLEX 18 News, and KMTA for their assistance with this report.

The Kentucky Fatality Assessment \& Control Evaluation Program (FACE) is funded by grant 2U60OH008483-09 from the Centers for Disease Control and Prevention and the National Institute for Occupational Safety and Health. The purpose of FACE is to aid in the research and prevention of occupational fatalities by evaluating events leading to, during, and after a work related fatality. Recommendations are made to help employers and employees have a safer work environment. For more information about FACE and KIPRC, please visit our website: www.kiprc.uky.edu 


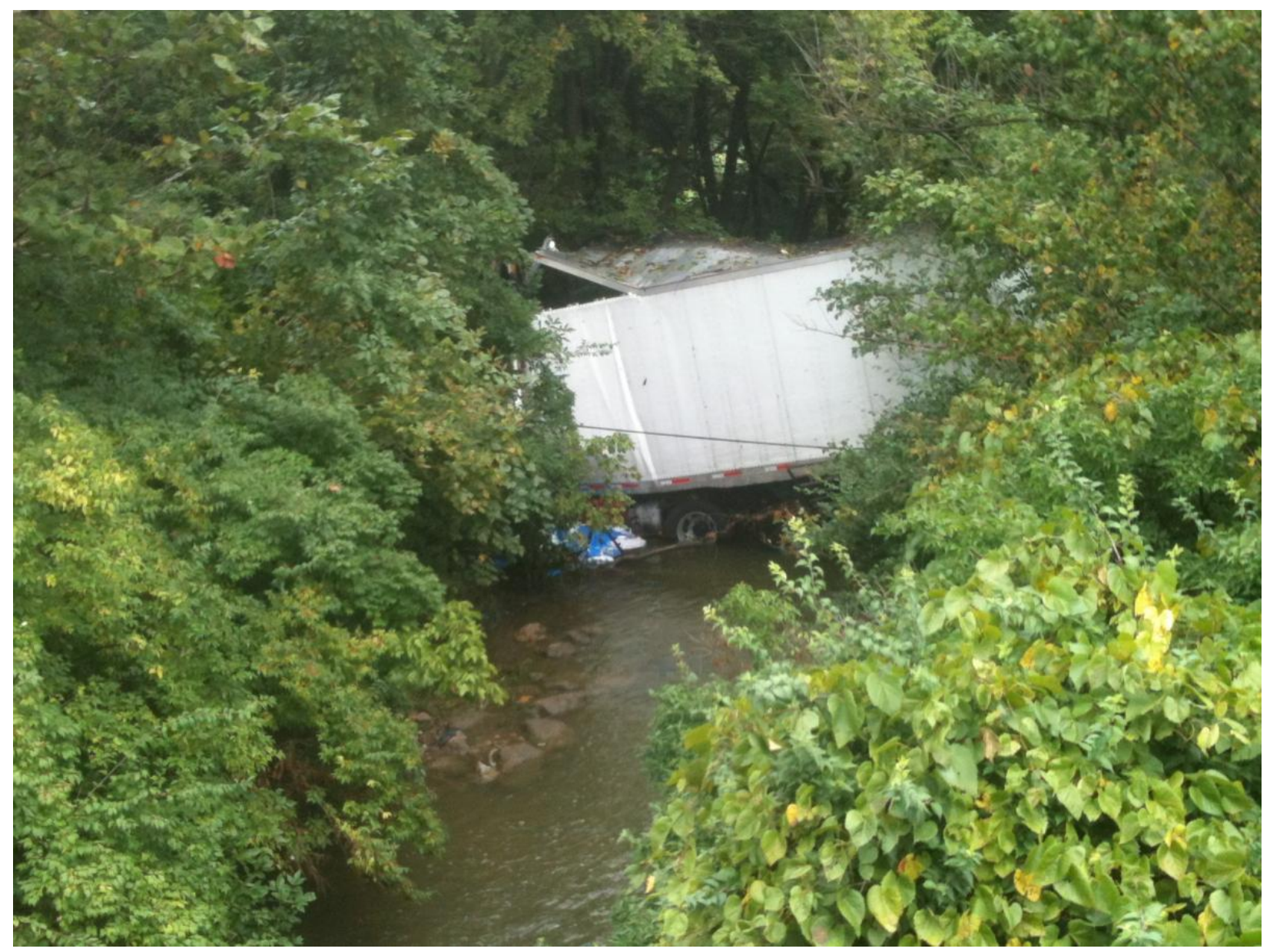

The creek where the truck landed after crashing. Picture courtesy of WLEX 18 News. 